\title{
A Novel Smart Tag-Based Vigilance System for Human Against Wildlife Threats on Iot
}

\author{
Andril Alagusabai, T.ShivaPrakash, N.P.Gopika
}

\begin{abstract}
India has 1.37 billion people and still the population is growing, therefore government is putting immense pressure on land to build homes and factories irrespective to wild inhabitants. Also, government in the process of taking endless effort in aspiration for economic growth of country by rushing through projects, sometimes without proper safeguards and deforestation. Deforestation and urbanisation are becoming a major concern. Which in turn results, human wildlife conflicts. This is a matter of serious alarm in balancing the competition for land between people and animals. Due to the above-mentioned reason the tribal people who dwell in and around the forest area suffer from the human and wild animal conflicts. The occurrence is mainly due to the unawareness of their migration of animal inhabitants in and around the living area due to scarcity of food and water. It has been visualized and propounded as an idea towards the people who dwell in the tribal forest areas, and encounter such kind of human wild life conflict problems through the articles in daily news. It's a major problem to be concerned, because this conflict has led to the extinction, reduction of numerous species, uncountable human deaths and economic losses. Recent advances in our understanding of conflict have led to a growing number of positive conservation but unfortunately with technology gaps.
\end{abstract}

Keywords - Digital Image processor, DBMS, Smart Tag

\section{INTRODUCTION}

In recent days the human-animal conflicts have been a major concern in the routine life of the tribal people residing on the boundaries of wildlife reserve area. There are other major issues that acts as the major causes of these conflicts. Unauthorized temple, new resorts and makeshifts shops has been recognized in the core part of the reserve areas in India. Also, its evidently found that many unauthorized shops are engaged more especially in the occasional festival seasons. In the long run, the officials of government have to immediately promulgate the ecologically sensitive zone to stop any more resorts in the core areas in order to address the human animals' conflicts.

\section{EXISTING SYSTEMS}

Many systems were articulated by the national governments organisations and government to overcome the existing conflicts between the human and animal.

Revised Manuscript Received on February 05, 2020.

* Correspondence Author

Andril Alagusabai, Assistant professor, Department of Electrical and Electronics Engineering, Bannari Amman Institute of Technology, Erode.

N.P.Gopika, Assistant professor,Department of Electrical and Electronics Engineering, Bannari Amman Institute of Technology, Erode.

T.Shiva Prakash, Pursuing, M.E in Power Electronics, Bannari Amman Institute of Technology, Erode.

(C) The Authors. Published by Blue Eyes Intelligence Engineering and Sciences Publication (BEIESP). This is an open access article under the CC BY-NC-ND license (http://creativecommons.org/licenses/by-nc-nd/4.0/)
Initially a system was created with a group of men to patrol the surviving boundary areas of the tribal people from the roof to, in case if there is any wild animal observed then they should give alert to their neighbour and people who living there, but this method has gave only $50 \%$ of success due to lack of human resources and misinterpretation among them. Then government in order to rectify the existing disadvantages evolved another arrangement by announcing in Radios but this method also got unsuccessful because those days the radios are very expensive, they were not able to get the individual radio for the houses so there are many lives had been lost.

In order, the successive system was to give an alarm system to the people, alarm in the sense of giving an alarm sound to the people in common place but this method also was disastrous, because the alarm sound irritates the animal psychologically with evident gradual change, which makes them more violent and anxious.

Yet again, the national government organisation came back with the recombination of the evolved systems method a group of men are at roof top in case the animal is observed an alert is given to the people by red alarming lights on the side of the animal arrival the light is glowed. This gave a 60 $70 \%$ of success rate.

Now a day's wild animals are in danger zone they getting extinct, in order to that they announced as reserved forest, due to this the tribal people living there should leave the forest. So, they suffered a lot for shelter, food, developing themselves among others.

\section{PROPOSED METHOD}

Here we have an idea to overcome these problems by Smart tag method that is if wild animal came into the surroundings of tribal people. The smart tag is given to the all tribal people to wear in their wrist, if any animal entered that surroundings, the tag gives a vibration alert to the individual people. So, they safeguard themselves from the animal. So that we can able to give a special attention to the animals without any man power.

\section{BLOCK DIAGRAM}

The Figure shows the single block diagram of the paper, that consists of six blocks they are Power supply, Camera, Digital Image Processor, DBMS, Tag indicator, Wi-Fi Router and smart tag. 


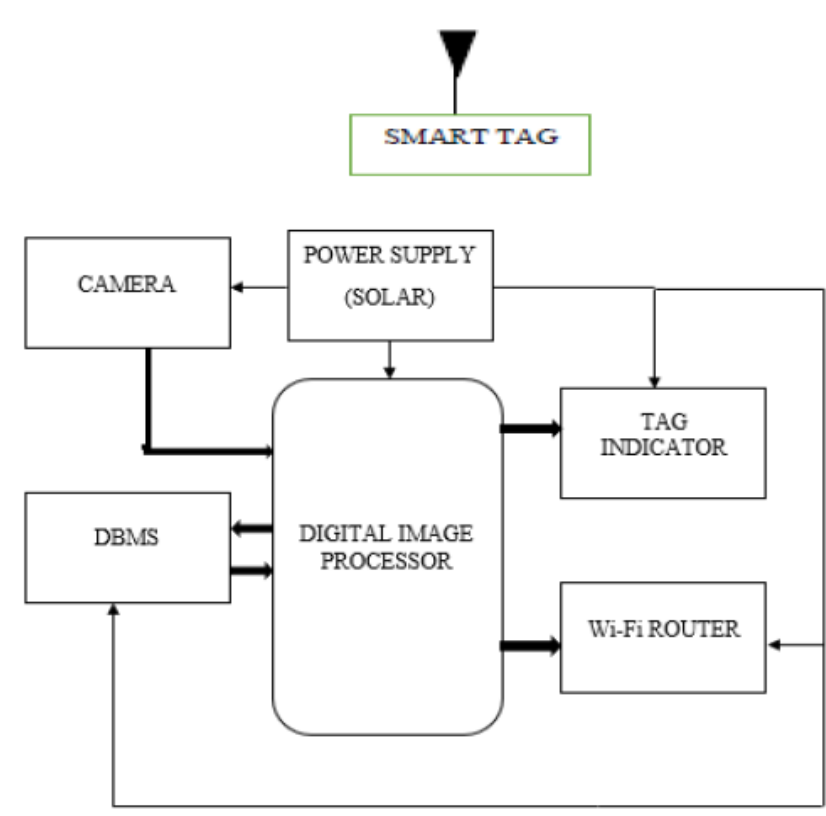

Fig.4.1 Generic Block

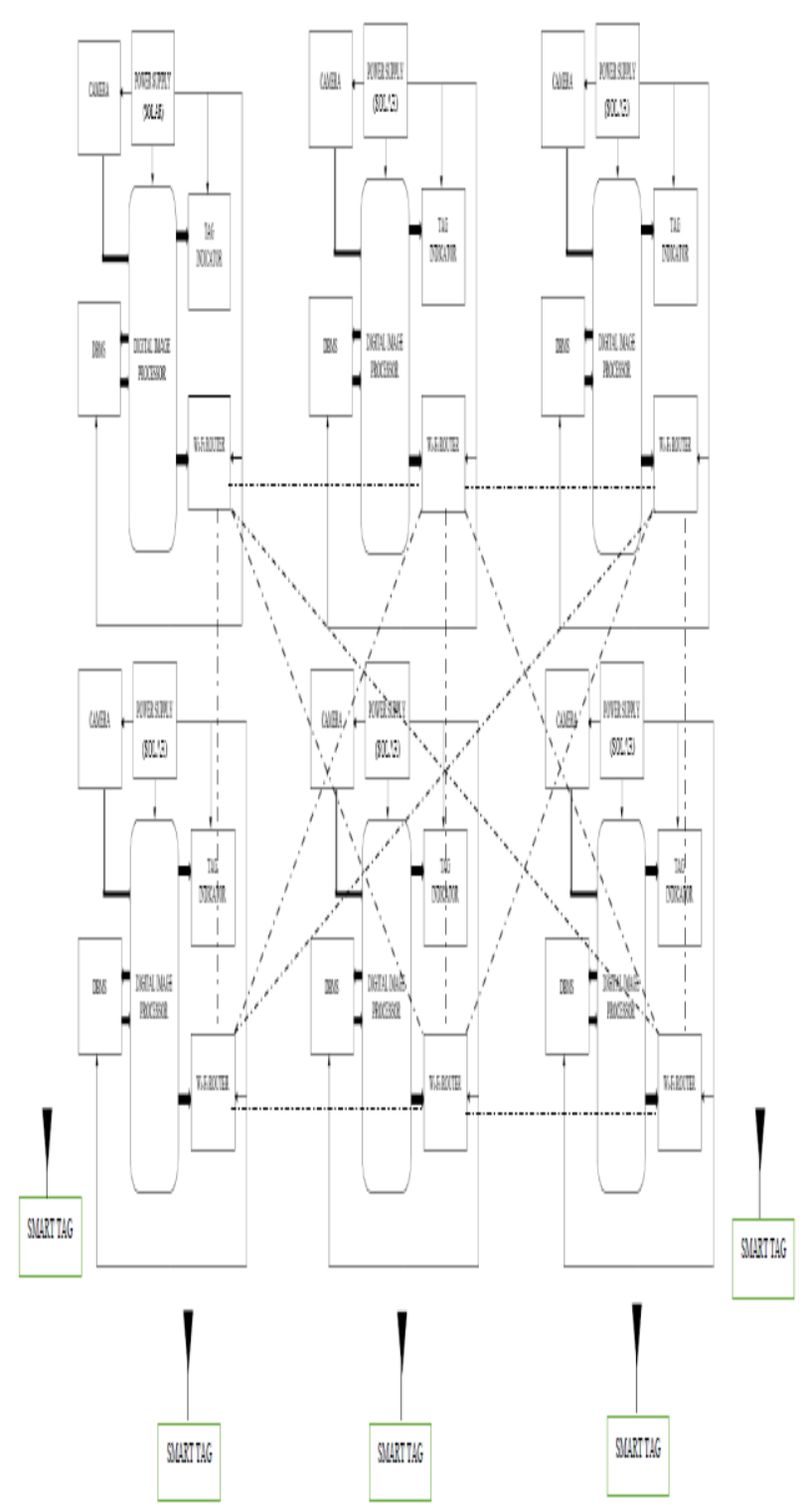

Fig.4.2 A novel smart tag based vigilance system for human against wildlife threats on IoT

\section{HARDWARE REQUIREMENTS}

\section{Power supply}

The power supply gives the power to the entire unit. Here the power supply is solar panel with battery backup. Smart tag runs by CMOS battery.

\section{Digital Image Processor}

Digital Image Processor is used to digitalize the image of wild animals. This processor not only digitalize the image it also controls the entire unit. In case the wild animal is capture in camera the processor give indication to tag indicator.

\section{Tag Indicator}

Tag Indicator is used to give alert message to smart tag, that tied in the wrist of each people.

\section{DBMS (Database Management System)}

Data Base Management System is used to store the entire data of wild animals. It not only stores the data of wild animals, whenever the camera capture symptoms of wild animal it used to retrieve the data.

\section{Camera}

A high-quality Camera is used to capture the symptoms and movements of wild animals. That gives the data to processor for indication via Tag Indicator and Smart tag.

\section{Wi-Fi Router}

Wi- Fi Router is used connect the entire single unit of the system that shares the data with each other and also stores in DBMS. Hence the Wi-Fi is used as a communication device for the entire systems.

\section{WORKING AND OPERATION}

The whole setup consists of $\mathrm{N}$ number of units that depends on the surrounding distance of the village. In this paper we are used 6 units. Each consists of a Camera, Digital Image Processor, DBMS, Tag Indicator, Power supply, Wi-Fi Router. Initially the motion, symptoms and nature of all wild are stored in the DBMS - Data Based Management System by Digital Image Processor as digitalized data.

The Camera is capturing the symptoms or any motions of wild animals. The Captured image is digitalized and Compared with existing data stored in the DBMS. Now the Digital Image Processor is used compare the data that stored in DBMS with the data acquired from the camera, Generally not all the animals are have same resembles even though it is the same specious hence in this if the acquired data and the stored are matched 60 percentage, then the processor will react according to that. In case the processor strikes that is the presence of wild animal, immediately the processor triggers the Tag Indictor, this indicator give alert to the all smart tag.

\section{Published By:}

Retrieval Number: C4913029320/2020@BEIESP 
The all tag indicator and the Smart tag connected in same frequency hence if any one of the units detects wild animal symptoms then it triggers all the smart tag.

Next the very important thing is Wi-Fi router in this this plays a major role in communication that is if any one of the devices is got failed the data present in that system also get collapsed for that this Wi-Fi router is used to connect all other systems with each other in wireless manner. The presence of $\mathrm{Wi}-\mathrm{Fi}$ is used to share the data among all the systems each and every system consists of all data that stored in the DBMS. The Last and final important operation is giving power to the entire unit of each system. Here we are using the solar panel and battery for the power supply. During the day time the power is taken from the solar panel and also stores it in battery for night usage and cloudy climate. Hence there is no interruption in power supply and there is no loss in data.

\section{RESULT}

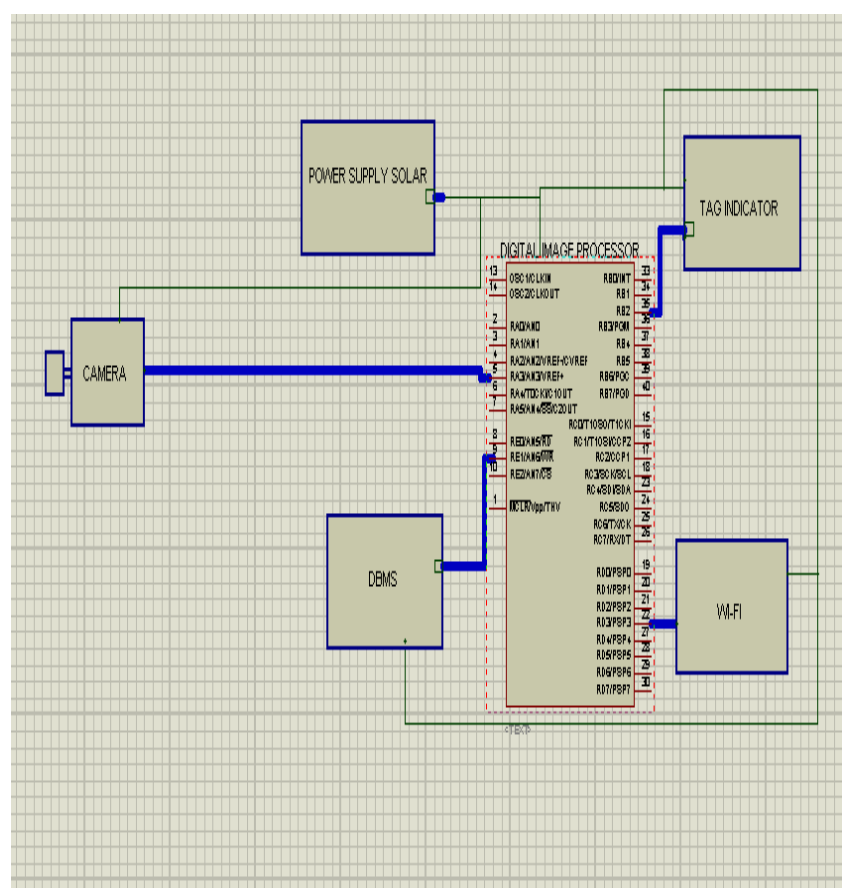

Fig:7.1 Simulated output

The above figure7.1 shows the simulated output of the proposed idea using proteus.

The system receives input from the environment as the image which is processed by the image processor. The processing includes the identification and comparison between the database and input retrieved. The database is maintained by the DBMS (Database Management system). The communication protocol used here to communicate with the nearer devices is wireless fidelity network.

If the input matches with the sample an alarm in given to the end user using a smart tag; Else, the vigilance continues to proceed.

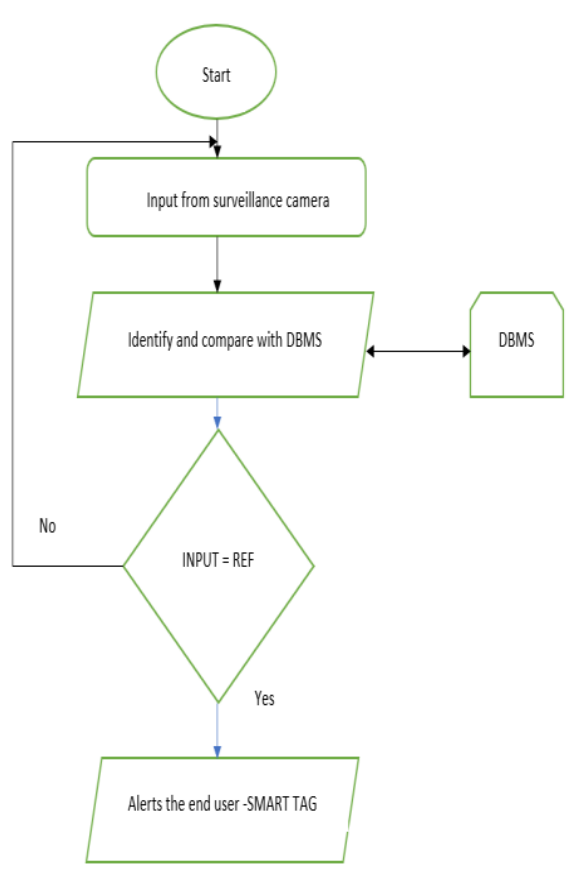

Fig 7.2 Flowchart of the vigilance system

\begin{tabular}{|c|c|c|}
\hline S. No & Input & Output Efficiency (\%) \\
\hline 1 & $\begin{array}{c}\text { Workman (used to intimate } \\
\text { the animals attack) }\end{array}$ & $>30 \%$ \\
\hline 2 & Television & $>40 \%$ \\
\hline 3 & Camera with IoT & $>90 \%$ \\
\hline
\end{tabular}

Table 1 Comparison chart between Input and Output efficiency

The above table. 1 shows the usage of input techniques and its corresponding output efficiency used since the ideas are conceived to rectify the conflicts between animal and humans.

\section{CONCLUSION}

Human Wildlife conflicts are typically not considered when the focus is on visible consequences like health impacts and threats to life on both sides mutually. Therefore, this paper has made efforts by involving the recent technologies that imbibe and make a system to reduce the impacts and conflicts between human and animal.

\section{REFERENCES}

1. RuthKanskya, MartinKiddb, Andrew T.Knight," A wildlife tolerance model and case study for understanding human wildlife conflicts"

2. Carl D. Soulsbury, and Piran C. L. White "Human-wildlife interactions in urban areas: a review of conflicts, benefits and opportunities" Wildlife Research 42(7) 541-553, 1 July 2015.

3. Krishna Prasad Acharya , Prakash Kumar Paudel, Prem Raj Neupane, Michael Kohl" Human-Wildlife Conflicts in Nepal: Patterns of Human Fatalities and Injuries Caused by Large Mammals" September 9, 2016.

4. Namita Gupta, Rajiv Kumar Gupta," Animal Welfare and Human Health: Rising Conflicts over Stray Dogs in Chandigarh "October 21 2019.

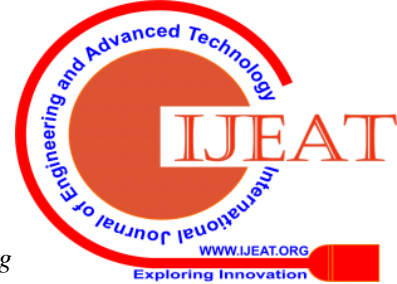


5. Denise F. Torres, Eduardo S. Oliveira, Rômulo R. N. Alves" Conflicts Between Humans and Terrestrial Vertebrates: A Global Review” August 22, 2018.

6. Dashper, K. (2017). Human-Animal Relationships in Equestrian Sport and Leisure. https://doi.org/10.4324/9781315678139

\section{AUTHOR PROFILE}

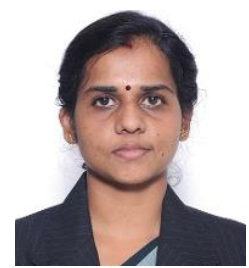

Andril Alagusabai, received B.E Degree in Electrical and Electronics Engineering from Sona college of Technology, Salem in 2011, M.E Degree in Embedded system and its technology from College of engineering Guindy in 2013.Currently he is an assistant professor of Electrical and Electronics Engineering at Bannari Amman Institute of Technology, Erode. His fields of interest include Embedded systems, Biomedical Instrumentation.

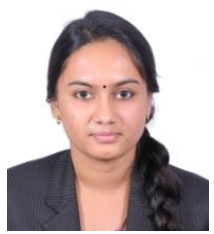

N.P.Gopika, received B.E Degree in Electrical and Electronics Engineering from USAT university in 2016, M.E Degree in Power and Energy systems from amrita school of engineeringi in 2019.Currently she is an Assistant professor of Electrical and Electronics Engineering at Bannari Amman Institute of Technology, Erode. Her fields of interest include smart grid and power quality.

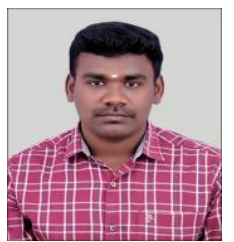

T.ShivaPrakash currently pursuing his M.E in Power Electronics at Bannari Amman Institute of Technology.s 